\title{
Comparative histological and immunohistochemical study of ameloblastomas and ameloblastic carcinomas
}

\author{
Marisol Martínez-Martínez ${ }^{1}$, Adalberto Mosqueda-Taylor ${ }^{2}$, Román Carlos-Bregni ${ }^{3}$, Fabio-Ramoa Pires ${ }^{4}$, \\ Wilson Delgado-Azañero ${ }^{5}$, Rodrigo Neves-Silva ${ }^{1}$, Beatriz Aldape-Barrios ${ }^{6}$, Oslei Paes-de Almeida ${ }^{1}$
}

\author{
${ }^{1}$ Oral Pathology Section, Department of Oral Diagnosis, Piracicaba Dental School, University of Campinas (UNICAMP), Pira- \\ cicaba, São Paulo, Brazil \\ ${ }^{2}$ Health Care Department, Universidad Autónoma Metropolitana, Xochimilco, Mexico \\ ${ }^{3}$ Pathology Section, Clinical Center of Head and Neck/Hospital Herrera Llerandi, Guatemala City, Guatemala \\ ${ }^{4}$ Department of Oral Pathology, University Federal Fulminense, Rio de Janeiro, Brazil \\ ${ }^{5}$ Department of Oral Pathology, Oral Medicine and Oral Surgery, Faculty of Dentistry, Universidad Peruana Ceyetano Heredia, \\ Lima, Peru \\ ${ }^{6}$ Professor of Oral Pathology, Faculty of Dentistry, Universidad Nacional Autónoma de México, Mexico
}

\section{Correspondence:}

Piracicaba Dental School

University of Campinas (UNICAMP)

Av. Limeira 901, P.O. Box 52, 13414-903

Piracicaba, São Paulo, Brazil

cdmarisolmtz@gmail.com

\begin{abstract}
Martínez-Martínez M, Mosqueda-Taylor A, Carlos-Bregni R, Pires FR, Delgado-Azañero W, Neves-Silva R, Aldape-Barrios B, Paes-de Almeida O. Comparative histological and immunohistochemical study of ameloblastomas and ameloblastic carcinomas. Med Oral Patol Oral Cir Bucal. 2017 May 1;22 (3):e324-32.

http://www.medicinaoral.com/medoralfree01/v22i3/medoralv22i3p324.pdf
\end{abstract}

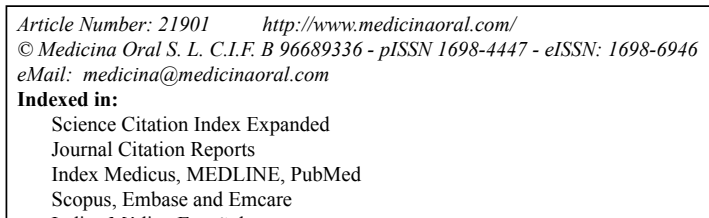

\begin{abstract}
Background: This study aimed to compare the histological and immunohistochemical characteristics of ameloblastomas (AM) and ameloblastic carcinomas (AC).

Material and Methods: Fifteen cases of AM and 9 AC were submitted to hematoxilin and eosin (H\&E) and immunohistochemical analysis with the following antibodies: cytokeratins 5,7,8,14 and 19, Ki-67, p53, p63 and the cellular adhesion molecules CD138 (Syndecan-1), E-cadherin and $\beta$-catenin. The mean score of the expression of $\mathrm{Ki}-67$ and p53 labelling index (LIs) were compared between the groups using the $\mathrm{t}$ test. A value of $p<0.05$ was considered to be statistically significant.

Results: All cases were positive for CKs 5, 14 and 19, but negative for CKs 7 and 8. CKs 5 and 19 were positive mainly in the central regions of the ameloblastic islands, while the expression in $\mathrm{AC}$ was variable in intensity and localization. CK14 was also variably expressed in both AM and AC. Ki-67 $(P=.001)$ and p53 $(P=.004)$ immunoexpression was higher in AC. All cases were positive for p63, but values were higher in AC. CD138 was mainly expressed in peripheral cells of AM, with a weak positivity in the central areas, while it was positive in most areas of ACs, except in less differentiated regions, where expression was decreased or lost. E-cadherin and $\beta$-catenin were weakly positive in both AM and AC.
\end{abstract}


Conclusions: These results shows that Ki-67, p53 and p63 expression was higher in AC as compared to AM, suggesting that these markers can be useful when considering diagnosis of malignancy, and perhaps could play a role in malignant transformation of AM. Pattern of expression of CKs 5 and 19 in AC were different to those found in AM, suggesting genetic alterations of these proteins in malignant cells. It was confirmed that CK19 is a good marker for benign odontogenic tumors, such as AM, but it is variably expressed in malignant cases.

Key words: Ameloblastoma, ameloblastic carcinoma, immunohistochemistry, odontogenic tumors.

\section{Introduction}

Ameloblastoma (AM) is one of the most common benign odontogenic neoplasms of the jaws, affecting mainly the posterior region of the mandible. It is locally aggressive, with a high rate of recurrence, while ameloblastic carcinoma (AC) is considered its malignant counterpart. Although rare, with less than 120 cases reported in the English literature, $\mathrm{AC}$ is the most common malignant odontogenic tumor (1). Microscopically it may show areas reminiscent of ameloblastoma, but with an invasive and less organized pattern, presenting atypia, mitoses and loss of typical ameloblastic morphology (2). Diagnosis of AC sometimes can be difficult, and both, clinical and histopathological features should be considered. The aim of this study was to compare the microscopic and immunohistochemical characteristics of 9 cases of $\mathrm{AC}$ and 15 of AM to determine the pattern of expression or differences in location or intensity of expression that may be of assistance in their differentiation.

\section{Material and Methods}

Fifteen cases of solid/multicystic AM and 9 AC were retrieved from the files of 5 Latin American oral pathology diagnostic services (Piracicaba Dental School, Brazil; Head and Neck Clinical Center, Guatemala; Peribact Private Service of Oral Pathology, Mexico; Oral Pathology Laboratory of the Universidad Autonoma Metropolitana Xochimilco, Mexico, and Oral Pathol- ogy Laboratory of the Universidad Peruana Cayetano Heredia, Peru). Clinical and radiographic data were retrieved from the patient's files when available. Histological hematoxylin and eosin (H\&E) stained sections of all cases were reviewed and diagnosis confirmed according to the current WHO Histological Classification of Tumors (3). For immunohistochemical analysis the following antibodies were used: cytokeratins 5,7,8,14 and 19, Ki-67, p53, p63 and the cellular adhesion molecules CD138 (Syndecan-1), E-cadherin and $\beta$-catenin (Table 1). For immunohistochemical staining $3 \mu \mathrm{m} \mathrm{sec}-$ tions of each case were used. Briefly, after antigen retrieval with EDTA/Tris buffer ( $\mathrm{pH}$ 9.0) in a microwave oven, endogenous peroxidase activity was blocked with $20 \% \mathrm{H}_{2} \mathrm{O}_{2}$. After overnight incubation, primary antibodies were detected by secondary antibodies labeled with estreptavidin-biotin-peroxidase, and the reaction developed with diaminobenzidine hydrochloride (DAB, Dako). The preparations were lightly counterstained with Carazzi hematoxylin, mounted with Canada balsam and examined by light microscopy. Immunohistochemical results were graded as negative (-) or positive $(+)$. Labeling index (LI) estimated with Ki-67 and p53 nuclear positiveness were evaluated in 5 selected epithelial areas that showed higher cellular density, using a 20X objective, and expressed in percentage using the ScanerScope System (Nuclear V9). The mean score of the expression of Ki-67 and p53 LIs were compared be-

Table 1: Antibodies used for immunohistochemical evaluation of 15 cases of ameloblastomas and 9 cases of ameloblastic carcinomas.

\begin{tabular}{|c|c|c|c|}
\hline Antibody & Clone & Dilution & Source \\
\hline CK5 & XM26 & $1: 400$ & Novocastra $^{a}$ \\
\hline CK7 & OV-TL $12 / 30$ & $1: 300$ & Dako $^{b}$ \\
\hline CK8 & CXL3 & $1: 400$ & Novocastra $^{\mathrm{a}}$ \\
\hline CK14 & LL 002 & $1: 200$ & Novocastra $^{\mathrm{a}}$ \\
\hline CK19 & RCK 108 & $1: 200$ & Dako $^{b}$ \\
\hline Ki-67 & MIB-1 & $1: 100$ & Dako $^{b}$ \\
\hline p53 & DO-7 & $1: 200$ & Dako $^{b}$ \\
\hline p63 & $4 \mathrm{~A} 4$ & $1: 300$ & Dako $^{b}$ \\
\hline $\begin{array}{c}\text { CD138 } \\
\text { (Syndecan-1) }\end{array}$ & MI15 & $1: 100$ & Dako $^{b}$ \\
\hline E-cad & 36B5 & $1: 200$ & Novocastra $^{\mathrm{a}}$ \\
\hline$\beta$-cat & $17 \mathrm{C} 2$ & $1: 200$ & Novocastra $^{\mathrm{a}}$ \\
\hline
\end{tabular}


tween the groups using the t test. A value of $p<0.05$ was considered to be statistically significant. This work was approved by the Ethics Committee in Research of the Piracicaba Dental School, University of Campinas, Brazil (registration number 120/2013).

\section{Results}

Among the 15 cases of AM there were 9 males and 6 females; age ranged from 11-58 yr. (mean age: 33.60 yr.). Nine cases involved the posterior mandible, and histologically all were of the solid type, 12 with predominant plexiform and 3 with follicular patterns. The stroma was variably collagenized, and in 4 cases it was focally myxoid.

$\mathrm{Ki}-67$ was mainly positive in some cells of the basal and suprabasal layers, but only occasional cells in the central areas similar to the stellate reticulum of the enamel organ were marked. The proliferative index varied between $0.35 \%$ and $6.89 \%$ with a mean of $2.37 \%$ (Fig. 1a). The localization and percentage of p53 immunostaining were similar to $\mathrm{Ki}-67$, but it was less intense, with values of positive nuclei between $0.13 \%$ and $5.90 \%$ and a mean of $1.77 \%$ (Fig. 1b). p63 was positive mainly in the columnar cells of the peripheral layer of the islands/ cords while in the central areas staining was variable, except for those areas of squamous metaplasia, which were positive in most cases (Fig. 1c).

Regarding CKs expression, CK5 appeared more intensely expressed in the central stellate reticulum-like areas than in the basal columnar cells, and it was positive in islands presenting flattened cells in both the peripheral and central areas (Fig. 1d), while in areas of squamous metaplasia it was variably expressed. CK14 expression was weak and diffuse in most cases, and



Fig. 1: Main immunohistochemical features in ameloblastoma: a. Ameloblastoma showing the nuclei of a few cells of the basal and suprabasal layers positive for Ki-67 (200X), b. Nuclear expression of p53 in AM, positive cells are evident, but the intensity of the staining is weak- arrows (200X), c. p63 immunostaining in ameloblastomas, showing epithelial islands intensely positive mainly in the peripheral cells, but many of the central cells also expressed this marker (200X), d. The central areas of the islands/cords were strongly positive for CK5, while the expression was weaker or negative on the peripheral columnar cells (200X), e. Follicular islands showing stronger expression in the central areas, but the basal layer was also positive. Arrow shows squamous metaplasia with cells weakly positive (200X), f. CK19 immunostaining in ameloblastoma, showing central cells intensely positive, with weak or negative expression in the basal and suprabasal layers $(400 \mathrm{X})$, g. Higher magnification of an epithelial island illustrating positiveness of CD138 mainly in the basal and suprabasal layers. Arrow shows squamous metaplasia, with peripheral cells exhibiting strong positivity, with the more central squamous cells loosening expression (400X), h. Central areas of an epithelial ameloblastic sheet showing positivity in cells presenting characteristics of squamous metaplasia (400X), i. Case of AM showing strong positiveness for $\beta$-catenin mainly in the peripheral columnar cells, loosing expression in some central cells. This strong staining was not common, as in most of the cases the labeling with $\beta$-catenin was weak or practically negative (200X). 
positiveness was mainly found in the stellate reticulumlike areas (Fig. 1e), but also in the basal layer of cystic areas, and it was weakly positive in some of the most superficial cells. CK19 showed strong expression in the central cells of the cords/islands, but it was weak or negative in the peripheral columnar cells (Fig. 1f). All cases of AM were negative for CK7 and CK8.

Among the adhesion molecules evaluated, CD138 was the most strongly expressed, particularly in the basal and suprabasal layers, while areas of squamous metaplasia were negative or weakly positive, while most central stellate reticulum-like cells were negative (Fig. $1 \mathrm{~g})$. E-cadherin expression in AM was not as evident as CD138, and in some cases staining was faint or practically negative. The basal and suprabasal cells exhibited a higher positivity than those located in the central areas. In some cases, groups of cells presenting squamous metaplasia were strongly positive, particularly when cell junctions were evident in H\&E (Fig. 1h). $\beta$-catenin was the least expressed of the three adhesion markers used, being weakly positive in most cases, except in areas with squamous metaplasia, where expression was more evident (Fig. 1i).

With respect to the 9 cases of $\mathrm{AC}$, there were 5 males and 4 females, with a mean age of 43.67 years (range: 22-65 years). The mandible was involved in 8 cases, 7 in the posterior region, and only one case occurred in the maxilla (Fig. 2). All cases were solid, with only one showing cystic areas. Most cases were composed by sheets of cells arranged in a plexiform pattern, but in 2 cases a follicular pattern predominated. The malignant epithelial cells showed pleomorphism and mitoses, and in six cases there were evidence of focal areas of necrosis. Some islands showed central areas similar to the stellate reticulum of the enamel organ, and most cases contained areas reminiscent of benign ameloblastoma but these were exceeded by the malignant component. The stroma usually was scarce and collagenized (Fig. $3)$.

Ki-67 proliferative index in AC ranged from 11.87\% to $53.29 \%$ (mean: $23.46 \%$ ), with positiveness in both peripheral and central cells (Fig. 4a). Regions similar to benign ameloblastoma exhibited a lower expression of $\mathrm{Ki}-67$, but these were not included for quantitation. The distribution of cells positive for p53 was similar as above described for $\mathrm{Ki}-67$, but the nuclei were much less intensely stained, with percentages of positive cells varying from $11.57 \%$ to $80.88 \%$ (mean: 36.01\%) (Fig. 4b). p63 expression was strongly positive in most cases and in most cells (Fig. 4c).

Expression of CK5 in AC was variable, as in 7 cases it was strongly positive either at the periphery or within
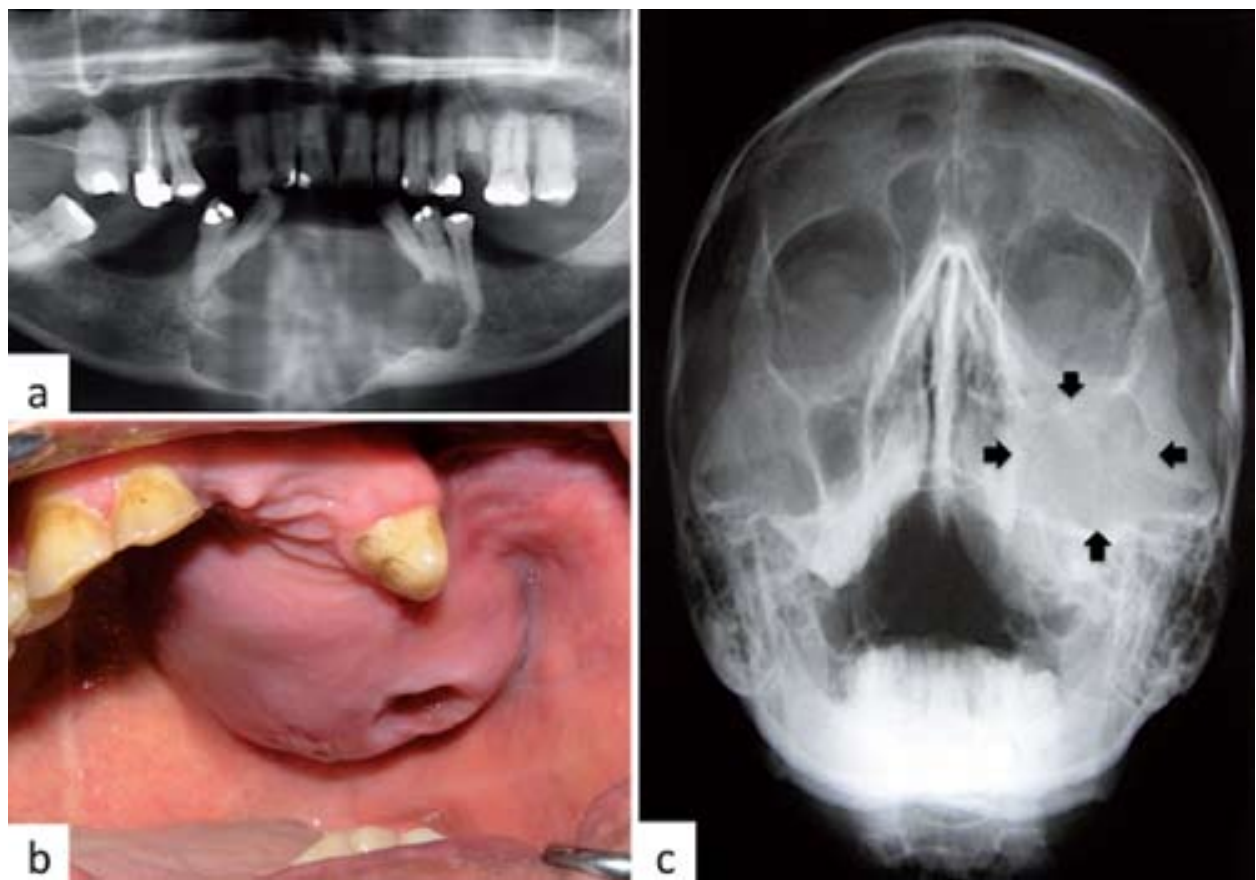

Fig. 2: Most cases of ameloblastic carcinoma involved the posterior mandible. This figure illustrates two unusual cases, one involving the anterior mandible and the other the left maxilla, a. Panoramic radiography showing irregular radiolucent lesion involving the anterior mandible causing tooth displacement, mobility and loss, b. AC of left maxilla affecting the alveolar ridge and extending into the palate. The perforation in the mucosa corresponds to a recent tooth extraction, c. Radiograph of the same case showing radiolucent image involving the left maxillary sinus and adjacent areas, including floor of the orbit. 

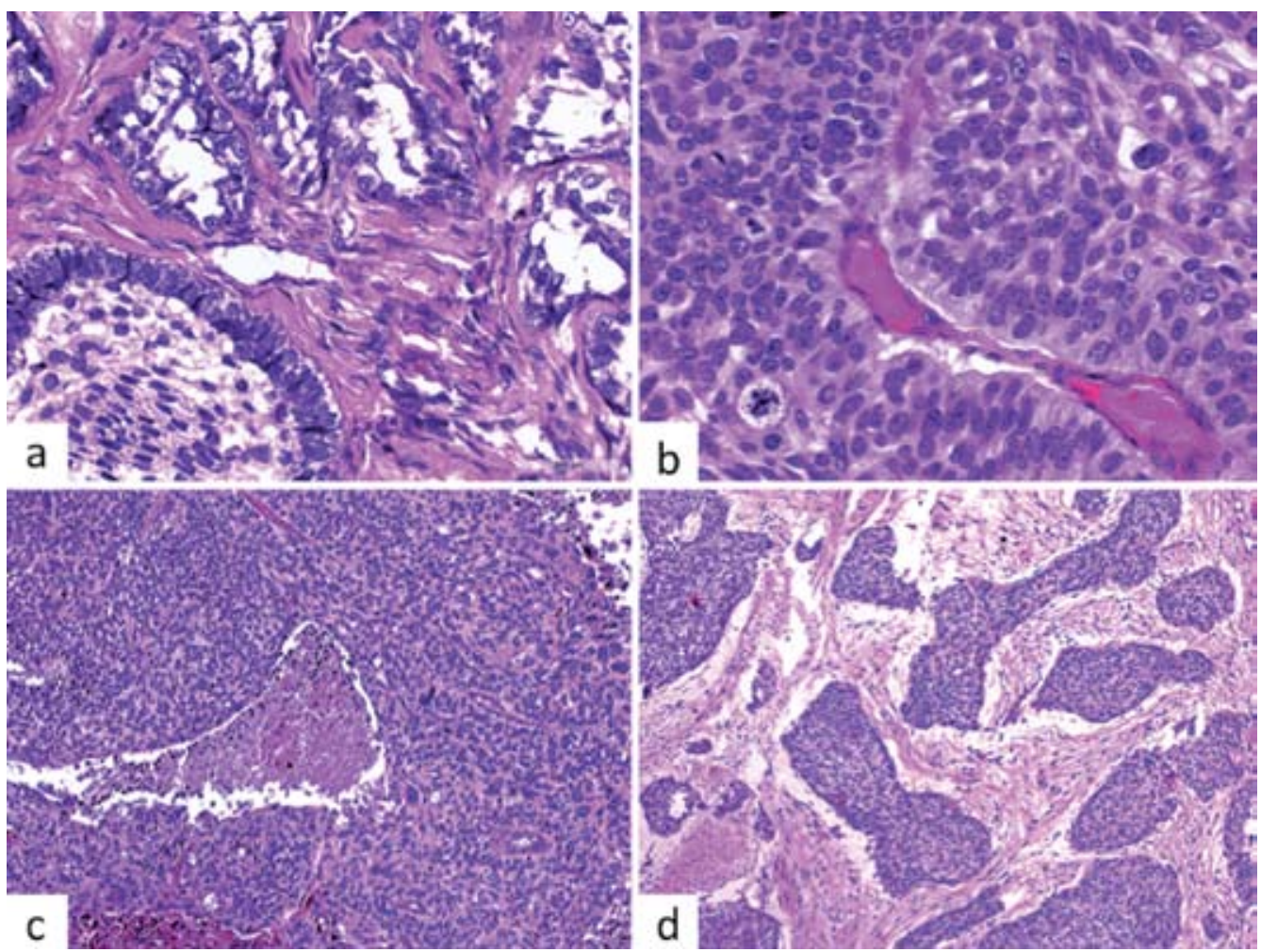

Fig. 3: Histological features of ameloblastic carcinoma, a. Epithelial islands with artefactual empty central spaces showing a follicular pattern, resembling an ameloblastic epithelium with columnar peripheral cells. The stroma is highly collagenized (H\&E, 400X), b. Sheets of malignant epithelial cells showing a peripheral layer formed by columnar cells, with ameloblastic characteristics, including reversal nuclear polarization. Cellular pleomorphism and atypical mitosis are evident (H\&E, 400X), c. Sheets of malignant epithelial cells showing a central area of necrosis (H\&E, 200X). d, Islands of well-defined malignant epithelium, with flattened peripheral cells separated by collagenized stroma. The islands are frequently separated from the adjacent stroma, suggesting a poor adherence of epithelium/ stroma adherence interface (H\&E, 200X).

the central epithelial cells, while two cases showed total or partial loss of CK5 in most areas, being positive only in a few more differentiated islands still showing ameloblastic characteristics (Fig. 4d). Expression of CK14 was also variable in intensity and localization, with 5 cases presenting positive expression in most of the cells, while in 4 it was either negative or focally positive (Fig. 4e). CK19 expression was not uniform, showing areas strongly positive mainly in a few islands with ameloblastic characteristics (Fig. 4f). Two cases of AC were focally positive for CK7 and CK8.

CD138 was strongly positive in most cases, except in very undifferentiated areas where its expression was lost or it was weakly positive (Fig. 4g). Expression of Ecadherin was variable both in intensity and localization (Fig. 4h). $\beta$-catenin expression was weak or negative in all but one case (Fig. 4i). Main immunoprofile and comparison between ameloblastomas and ameloblastic carcinoma are shown in table 2 .

\section{Discussion}

AMs are locally aggressive benign tumors with a relatively high risk of recurrence and potential to malignant transformation into AC. Up to date, there are around 120 cases of AC reported in the English literature, some of which seem to have developed from AM (4-5). Radiographically, AM may appear either as uni or multilocular osteolytic lesions that frequently produce cortical expansion. If paresthesia, pain, irregular borders and invasion of adjacent structures are present, then a malignant lesion should be suspected $(2,6)$.

In contrast to AM, ACs usually present microscopic evidence of malignancy, but confirmation of the diagnosis of a secondary type of AC (those developed from a pre-existent AM) need to be supported by a history of persistent or recurrent $\mathrm{AM}$, or the presence of benign residual areas of AM; eventually, differential diagnosis between these two lesions can be difficult, particularly in incisional biopsies, and therefore other types of intraosseous carcinomas of the jaws should be considered. Immunohistochemistry is not usually employed to assist diagnosis and classification of odontogenic tumors, but some immunomarkers may be useful for a better understanding of their origin and possible biological behavior, and therefore the immunohistochemical profile of these lesions may sometimes be helpful to reach 

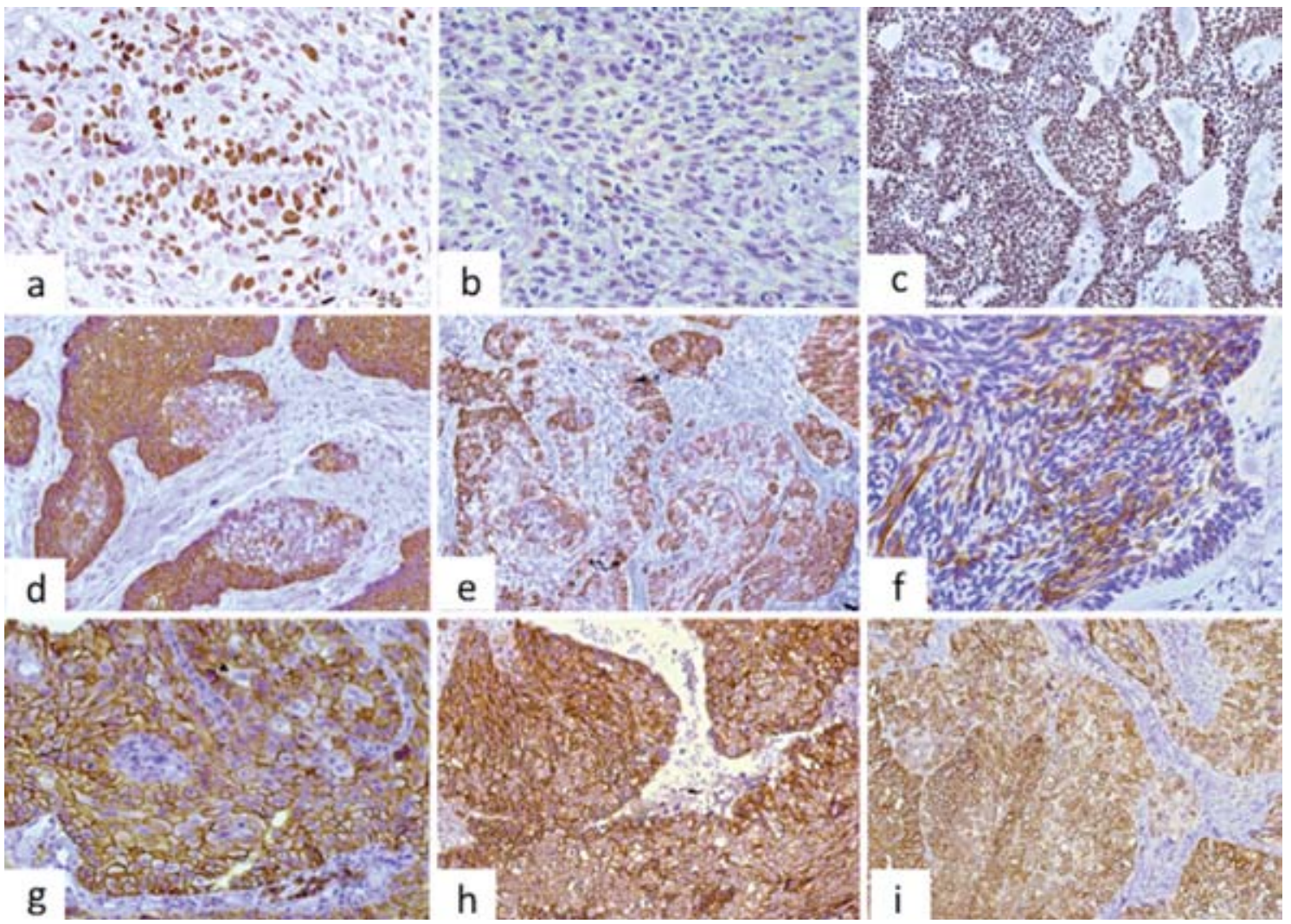

Fig. 4: Main immunohistochemical features in ameloblastic carcinoma: a. Epithelial cells showing strong and high expression of $\mathrm{Ki}-67$ in most of the cells (200X), b. Nuclear expression of p53 in AC, positive cells are evident, but the intensity of the staining is weak (200X), c. p63 immunostaining in ameloblastic carcinoma, with most of the nuclei strongly positive (200X), d. Strong and homogenous expression of $\mathrm{CK} 5$ in $\mathrm{AC}$, both in the central and peripheral cells of the epithelial islands, with loss of expression in focal areas (200X), e. Neoplastic islands illustrating strong expression for CK14 in most cells, but loss of staining or weak expression in focal regions (200X), f. CK19 staining in ameloblastic carcinoma, showing strongly positive cells permeated by negative cells in both peripheral and central areas (200X), g. epithelial malignant sheet showing most cells with strong positivity for CD138 (400X), h. Case of AC strongly expressing E-cadherin in most of the cells; nevertheless, expression was variable in most cases, and some were negative (200X), i. Case of AC showing strong expression of $\beta$-catenin. In most cases it was weakly positive or negative (200X).

a correct diagnosis in doubtful situations. The present series confirms that Ki-67 proliferative index $(P=.001)$ and p53 expression $(P=.004)$ are higher in ACs than in AMs. These results confirm that Ki-67 immunoexpression is a useful tool to distinguish among benign and malignant tumors, as it has been demonstrated in the malignant areas of other tumors, such as carcinoma exPA with scant areas of malignancy that are not clearly evident under H\&E stained sections (7-8). The higher expression of $\mathrm{p} 53$ found in ACs as compared to AMs suggest that this protein may play a role in malignant transformation, as has been also suggested by other authors (9-11). However, data regarding p53 expression in ACs varies in different studies; for example, studies performed by Yoon et al., (2); Karakida et al., (12); Matsuzaki et al. (10), and Nobusawa et al., (13) described p53 overexpression in almost all tumor cells of the carcinoma component, while it was negative in the benign ameloblastic areas; however, Abiko et al. (14) found that both benign and malignant areas of one case of $\mathrm{AC}$ were negative for $\mathrm{p} 53$ by immunohistochemistry. In our opinion the information obtained in a single case is not enough to compare with our findings, and with those found by the other authors that based their studies in series of cases that have followed a similar sample processing and analysis, with less probabilities of misdiagnosis and technical errors.

It is well known that CKs 14 and 19 are regularly expressed in the epithelium of the dental germ, where CK14 is found in the diverse components during all stages of tooth development, including the dental lamina, the inner enamel epithelium and in almost all cells of the enamel organ, while CK19 is mainly positive in the later stages of development, during terminal differentiation of ameloblasts $(15,16)$. We found a similar pattern of expression of these proteins in $\mathrm{AM}$, but it was different to the one observed in $\mathrm{AC}$ since in the malignant tumor the expression was irregular in intensity and location for both CKs. CKs 5, which was less expressed in $\mathrm{AC}$ than in AM and CK14 seem to be the major CKs 
Table 2: Comparison of the main immunohistochemical features of 15 cases of ameloblastomas and 9 cases of ameloblastic carcinomas observed in this series.

\begin{tabular}{|c|c|c|}
\hline Marker & Ameloblastoma (AM) & Ameloblastic Carcinoma (AC) \\
\hline Ki-67 & $\begin{array}{l}\text { Expression in basal and suprabasal cells. } \\
\text { Occasional in central areas. }(2.37 \%)\end{array}$ & $\begin{array}{l}\text { Highest expression in basal and suprabasal cells. } \\
\qquad(23.46 \%)\end{array}$ \\
\hline p53 & $\begin{array}{l}\text { Weak expression in basal and suprabasal } \\
\text { cells. Focal in central areas. }(1.77 \%)\end{array}$ & $\begin{array}{c}\text { High expression in basal and suprabasal cells, } \\
\text { but the nuclei were much less intensely stained. } \\
(36.01 \%)\end{array}$ \\
\hline p63 & $\begin{array}{l}\text { Positive mainly in the columnar cells of the } \\
\text { peripheral layer while in the central areas was } \\
\text { variable. Squamous metaplasias were positive } \\
\text { in most cases. }\end{array}$ & $\begin{array}{l}\text { Strong positiveness in most cases and in most of } \\
\text { the cells. }\end{array}$ \\
\hline CK5 & $\begin{array}{l}\text { Strong expression in the central areas of the } \\
\text { epithelial islands and weak or negative in the } \\
\text { peripheral columnar cells except in the cells } \\
\text { with flattened and cuboidal aspect. }\end{array}$ & $\begin{array}{l}\text { Strongly positive at the periphery or within the } \\
\text { central epithelial cells, while two cases showed } \\
\text { total or partial loss in most areas. }\end{array}$ \\
\hline CK14 & $\begin{array}{l}\text { Weak and diffuse expression in the central } \\
\text { areas, while weak or negative in focal areas } \\
\text { with squamous metaplasia. }\end{array}$ & $\begin{array}{l}\text { Variable in intensity and localization, with } 5 \\
\text { cases presenting positive expression in most of } \\
\text { the cells, while in } 4 \text { it was either negative or } \\
\text { focally positive. }\end{array}$ \\
\hline CK19 & $\begin{array}{l}\text { Strong expression in the central areas and } \\
\text { weak or negative in the peripheral columnar } \\
\text { cells except in the cells with flattened and } \\
\text { cuboidal aspect. }\end{array}$ & $\begin{array}{l}\text { It was not uniform, showing areas strongly } \\
\text { positive, mainly in a few islands with } \\
\text { ameloblastic characteristics }\end{array}$ \\
\hline CD138 & $\begin{array}{c}\text { Higher expression in the basal and suprabasal } \\
\text { layers }\end{array}$ & $\begin{array}{l}\text { Strongly positive in most cases, except in very } \\
\text { undifferentiated areas where its expression was } \\
\text { lost or it was weakly positive }\end{array}$ \\
\hline E-cad & $\begin{array}{c}\text { Higher positivity in basal and suprabasal cells } \\
\text { than those located in the central areas. In } \\
\text { squamous metaplasia focal cells were } \\
\text { strongly positive. }\end{array}$ & $\begin{array}{l}\text { Variable either in intensity or localization, with } \\
\text { some cases being strongly positive in focal areas } \\
\text { while others were considered negative. }\end{array}$ \\
\hline B-cat & $\begin{array}{l}\text { Weakly positive in most cases, except in } \\
\text { areas with squamous metaplasia, where } \\
\text { expression was more evident. }\end{array}$ & Weak or negative in all cases. \\
\hline
\end{tabular}

expressed by epithelium in the human enamel organ, marking the end of secretion of amelogenin (17).

CK8 is found in embrionary and several simple epithelia, as well as in the human enamel organ, but Crivellini et al., concluded that CK8 was absent in odontogenic epithelium, as it was observed in most cases in our study.

CK19 expression has been demonstrated in most odontogenic cysts and benign tumors, and it has been considered a good marker for benign odontogenic lesions (14). Nevertheless it is also expressed in AC and therefore has no diagnostic utility to differentiate among these entities $(18,19)$. In the present study, CK19 expression in $\mathrm{AC}$ was variable, being usually maintained in areas with ameloblastic characteristics.

p63 is expressed in normal epithelium and it is often overexpressed in carcinomas, including oral squamous cell carcinoma (20). It is also overexpressed in odontogenic carcinomas, such as AC, primary intraosseous squamous cell carcinoma and clear cell carcinoma as compared to benign odontogenic lesions, suggesting that p63 may have a role in tumorigenesis of odontogenic lesions (21). In the present study, p63 was mainly expressed in the basal and suprabasal cells of AM, in a pattern previously observed in odontogenic keratocyst, suggesting that this protein is a good marker of more immature keratinocytes (22). Different from AM, p63 was overexpressed in all our cases of AC, labeling most of the cells, in a similar way as it occur in other types of carcinomas, indicating lack of cell differentiation and a higher potential for growth, two common characteristics of malignancies (23).

Cell adhesion molecules and their interactions can be altered in tumors, particularly in malignancies, favoring progression, invasion, recurrence and metastasis (5). In normal conditions, E-cadherin is moderately expressed in odontogenic epithelium during the bell stage, especially in the stellate reticulum of the enamel organ, and also in the polyhedral cells of ameloblastomas (24). $\beta$-catenin is a multifunctional molecule that plays a role in cell-cell adhesion mediated by classic cadherins as well as in Wnt-signaling (25). CD138 is a cell surface proteoglycan present in normal epithelial cells, whose expression seems to decrease in ameloblastomas, as compared to epithelial cells of normal enamel organ, having also an inverse relation with cell proliferation index, aggressiveness and recurrence (26-28). There are some studies that have demonstrated positive expression of CD138 in AM, both in the columnar and the polyhedral cells of the stellate reticulum (29), and nu- 
clear expression of E-cadherin and $\beta$-catenin have been reported in cases of solid AM and odontogenic carcinomas (25). In this study, CD138 was the most strongly expressed adhesion molecule, both in $\mathrm{AM}$ and $\mathrm{AC}$, while E-cadherin and $\beta$-catenin expression was faint in most of the cases. These last two markers were intensely positive only in areas of squamous metaplasia of AMs, particularly when desmosomes were evident in H\&E stained preparations. CD138 expression was faint or negative only in the central areas of AMs islands where cells were loosely adhered, leaving spaces between them. CD138 was positive in most areas of AC, except in the less differentiated regions, where expression was decreased or lost. However, our data does not allow us to confirm that there is a higher loss of these molecules in $\mathrm{AC}$ as compared to $\mathrm{AM}$, and therefore more studies are necessary to determine if loss of expression of these proteins can be relevant to support malignant transformation or higher aggressiveness in these neoplasms. As mentioned above, expressions of E-cadherin and $\beta$-catenin were weak in AMs and ACs, difficulting analysis about their possible role in these neoplasms.

In summary, the results of this work confirmed that patients with $\mathrm{AC}$ were about a decade older than those with AM. Ki-67 and p53 immunoexpression was higher in $\mathrm{AC}$ than in $\mathrm{AM}$, supporting the idea that they can be good markers of malignant transformation. p63 was also more frequently expressed in AC, suggesting loss of maturation of the malignant epithelial cells. The pattern of expression of CKs 5 and 19 is altered in AC in relation to AM, but this does not seem to be related to malignant transformation. Finally, we could not find evident loss of the adhesion molecules CD138, E-cadherin and $\beta$-catenin in $\mathrm{AC}$ in relation to $\mathrm{AM}$, but as $\mathrm{ACs}$ are very rare lesions, we suggest that new series of cases need to be studied for a better understanding of its clinical and biological aspects.

\section{References}

1. Martínez Martínez M, Mosqueda-Taylor A, Carlos R, DelgadoAzañero W, de Almeida OP. Malignant odontogenic tumors: a multicentric Latin American study of 25 cases. Oral Dis. 2014;20:380-5.

2. Yoon HJ, Hong SP, Lee JI, Lee SS, Hong SD. Ameloblastic carcinoma: an analysis of 6 cases with review of the literature. Oral Surg Oral Med Oral Pathol Oral Radiol Endod. 2009;108:904-13.

3. Barnes L, Eveson JW, Reichart PA, et al. World Health Organization Classification Of Tumours: Pathology and Genetics of Tumours of the Head and Neck. Lyon: IARC. 2005.

4. Lesot H, Brook AH. Epithelial histogenesis during tooth development. Arch Oral Biol. 2009;54:S25-33.

5. Costa P, Parsons M. New insights into the dynamics of cell adhesions. Int Rev Cell Mol Biol. 2010;283:57-91.

6. Fregnani ER, da Cruz Perez DE, de Almeida OP, Kowalski LP, Soares FA, de Abreu Alves F. Clinicopathological study and treatment outcomes of 121 cases of ameloblastomas. Int J Oral Maxillofac Surg. 2010;39:145-9.

7. Costa AF, Altemani A, Hermsen M. Current concepts on dedifferentiation/high-grade transformation in salivary gland tumors. Patholog Res Int. 2011;2011:325965.
8. do Prado RF, da Silva Machado AL, Colombo CE, Carvalho YR. Immunohistochemical study of the expression of fatty acid synthase and Ki-67 in salivary gland tumors. J Oral Pathol Med. 2011;40:46775 .

9. Al-Salihi KA, Ling Yoke LI, Azlina A. P53 gene mutation and protein expression. in ameloblastomas. Braz J Oral Sci. 2006;17:103440.

10. Matsuzaki H, Katase N, Hara M, Asaumi J, Yanagi Y, Unetsubo $\mathrm{T}$, et al. Ameloblastic carcinoma: a case report with radiological features of computed tomography and magnetic resonance imaging and positron emission tomography. Oral Surg Oral Med Oral Pathol Oral Radiol Endod. 2011;112:e40-7.

11. Loyola AM, Cardoso SV, de Faria PR, Servato JP, Eisenberg AL, Dias FL, et al. Ameloblastic carcinoma: a Brazilian collaborative study of 17 cases. Histopathology. 2016;69:687-701.

12. Karakida K, Aoki T, Sakamoto H, Takahashi M, Akamatsu T, Ogura G, et al. Ameloblastic carcinoma, secondary type: a case report. Oral Surg Oral Med Oral Pathol Oral Radiol Endod. 2010;110:e33-7.

13. Nobusawa A, Sano T, Yokoo S, Oyama T. Ameloblastic carcinoma developing in preexisting ameloblastoma with a mutation of the p53 gene: a case report. Oral Surg Oral Med Oral Pathol Oral Radiol. 2014;118:e146-50.

14. Abiko Y, Nagayasu H, Takeshima M, Yamazaki M, Nishimura M, Kusano K, et al. Ameloblastic carcinoma ex ameloblastoma: report of a case-possible involvement of $\mathrm{CpG}$ island hypermethylation of the p16 gene in malignant transformation. Oral Surg Oral Med Oral Pathol Oral Radiol Endod. 2007;103:72-6.

15. Crivelini MM, de Araújo VC, de Sousa SO, de Araújo NS. Cytokeratins in epithelia of odontogenic neoplasms. Oral Dis. 2003;9:1-6. 16. Kaminagakura E, Domingos PL, da Rosa MR Loyola AM, Cardoso SV, Lopes MC, et al. Detection of cytokeratins in ghost cells of calcifying cystic odontogenic tumor indicates an altered keratinization and hair follicle differentiation for their development. Ann Diagn Pathol. 2013;17:514-7.

17. Arzi B, Murphy B, Nemec A, Vapniarsky N, Naydan DK, Verstraete FJ. Expression of cytokeratins in the epithelium of canine odontogenic tumours. J Comp Pathol. 2011;145:345-51.

18. Hunter KD, Speight PM. The diagnostic usefulness of immunohistochemistry for odontogenic lesions. Head Neck Pathol. 2014;8:392-9.

19. Martínez-Martínez M, Mosqueda-Taylor A, Delgado-Azañero W, Rumayor-Piña A, de Almeida OP. Primary intraosseous squamous cell carcinoma arising in an odontogenic keratocyst previously treated with marsupialization: case report and immunohistochemical study. Oral Surg Oral Med Oral Pathol Oral Radiol. 2016;121:87-95. 20. Varun BR, Ranganathan K, Rao UK, Joshua E. Immunohistochemical detection of $\mathrm{p} 53$ and p 63 in oral squamous cell carcinoma, oral leukoplakia, and oral submucous fibrosis. J Investig Clin Dent. 2014;5:214-9.

21. Lo Muzio L, Santarelli A, Caltabiano R, Rubini C, Pieramici T, Giannone N, et al. p63 expression correlates with pathological features and biological behaviour of odontogenic tumours. Histopathology. 2006;49:211-4.

22. Takeda T, Sugihara K, Hirayama Y, Hirano M, Tanuma JI, Semba I. Immunohistological evaluation of Ki-67, p63, CK19 and p53 expression in oral epithelial dysplasias. J Oral Pathol Med. 2006;35:369-75

23. Atarbashi Moghadam S, Atarbashi Moghadam F, Mokhtari S, Eini E. Immunohistochemical analysis of P63 expression in odontogenic lesions. Biomed Res Int. 2013;2013:624176.

24. Kumamoto H, Ooya K. Expression of E-cadherin and alphacatenin in epithelial odontogenic tumors: an immunohistochemical study. J Oral Pathol Med. 1999;28:152-7.

25. Alves Pereira KM, do Amaral BA, dos Santos BR, Galvão HC, Freitas Rde A, de Souza LB. Immunohistochemical expression of Ecadherin and beta-catenin in ameloblastomas and tooth germs. Oral Surg Oral Med Oral Pathol Oral Radiol Endod. 2010;109:425-31.

26. Bologna-Molina R, Mosqueda-Taylor A, Lopez-Corella E, Al- 
meida OP, Carrasco-Daza D, Garcia-Vazquez F, et al. Syndecan-1 (CD138) and Ki-67 expression in different subtypes of ameloblastomas. Oral Oncol. 2008;44:805-11.

27. Bologna-Molina R, Mosqueda-Taylor A, Lopez-Corella E, de Almeida OP, Carrasco-Daza D, Farfán-Morales JE, et al. Comparative expression of syndecan-1 and Ki-67 in peripheral and desmoplastic ameloblastomas and ameloblastic carcinoma. Pathol Int. 2009;59:229-33.

28. Safadi RA, Quda BF, Hammad HM. Immunohistochemical expression of K6, K8, K16, K17, K19, maspin, syndecan-1 (CD138), $\alpha$-SMA, and $\mathrm{Ki}-67$ in ameloblastoma and ameloblastic carcinoma: diagnostic and prognostic correlations. Oral Surg Oral Med Oral Pathol Oral Radiol. 2016;121:402-11.

29. Bologna-Molina R, Mosqueda-Taylor A, de Almeida-Oslei P, Toral-Rizo V, Martínez-Mata G. Peripheral desmoplastic ameloblastoma: histopathological and immunohistochemical profile of a case. Med Oral Patol Oral Cir Bucal. 2010;15:e846-9.

\section{Conflict of Interest}

The authors have declared that no conflict of interest exist. 